\title{
Dose reduction of inhaled corticosteroids under concomitant medication with montelukast in patients with asthma
}

\author{
F. Kanniess, K. Richter, S. Janicki, M.B. Schleiss, R.A. Jörres, H. Magnussen
}

\begin{abstract}
Dose reduction of inhaled corticosteroids under concomitant medication with montelukast in patients with asthma. F. Kanniess, K. Richter, S. Janicki, M.B. Schleiss, R. A. Jörres, H. Magnussen. (C) ERS Journals Ltd 2002.

ABSTRACT: The present study aimed at comparing the effects of a dose reduction of inhaled corticosteroids on lung function, indirect measures of airway inflammation and clinical scores during treatment with a leucotriene receptor antagonist.

In 50 patients (mean forced expiratory volume in one second (FEV1) 94\% predicted), steroid doses $(800 \mu \mathrm{g}$ beclomethasone dipropionate) were first reduced to $50 \%$ and then to $25 \%$, for 6 weeks each. One group received a placebo and the other group received montelukast $(10 \mathrm{mg})$.

The first reduction did not cause significant effects. During the second, FEV1 and peak expiratory flow decreased in both groups $(p<0.001)$. Daytime symptoms were not altered with placebo but were reduced by montelukast $(p<0.05)$. Night-time symptoms were slightly elevated with placebo $(p<0.05)$ but not montelukast, as well as the use of supplemental salbutamol. Changes in provocative concentration of methacholine causing a 20\% fall in FEV1 (PC20), sputum eosinophils and exhaled nitric oxide were mostly nonsignificant for both placebo and montelukast.

These data demonstrate that a $75 \%$ reduction in the dose of steroid given to patients with asthma led to a deterioration in lung function not prevented by montelukast, whereas changes in clinical state seemed to favour montelukast treatment. It therefore appears that potential effects of montelukast, in the presence of low-dose steroids, could not be attributed to single indices of lung function or airway inflammation.
\end{abstract} Eur Respir J 2002; 20: 1080-1087.
Pulmonary Research Institute, Hospital Großhansdorf, Center for Pneumology and Thoracic Surgery, Großhansdorf, Germany.

Correspondence: F. Kanniess, Pulmonary Research Institute, Hospital Großhansdorf, Center for Pneumology and Thoracic Surgery, Wöhrendamm 80, D-22927 Großhansdorf, Germany. Fax: 494102601379

E-mail: f.kanniess@pulmoresearch.de

Keywords: Airway hyperresponsiveness airway inflammation

leucotriene receptor antagonist

lung function

methacholine

steroid reduction

Received: December 192001

Accepted after revision: June 302002

Supported by an educational grant from MSD, Munich, Germany
Bronchial asthma is defined as an inflammatory airway disease characterised by intermittent to chronic airway obstruction and bronchial hyperresponsiveness to pharmacological and physical stimuli [1]. The presence of airway inflammation has been extensively demonstrated through bronchial biopsies [2] and also by noninvasive markers such as sputum eosinophils and exhaled nitric oxide nitric oxide (NO), both of which appear to be highly sensitive to the effects of anti-inflammatory treatment [3-7].

The most potent anti-inflammatory drugs in asthma are glucocorticosteroids. The regular use of inhaled corticosteroids is recommended in international guidelines as first-line treatment [1]. Corticosteroids, however, do not fully suppress the production or release of all inflammatory mediators [8]. Amongst those less affected are cysteinyl leucotrienes, which are known to play a key role in asthma [9]. However, whether clinically introduced antileucotrienes exert significant anti-inflammatory effects is still under discussion. Some studies have shown a reduction in, for example, sputum eosinophils or the level of exhaled NO, whilst others have not [10-12]. Irrespective of this, antileucotrienes undisputedly have a bronchodilator and bronchoprotective potential $[12,13]$ and have thus became part of current treatment recommendations in asthma [1].

Owing to the beneficial effects of antileucotrienes and the efforts to keep steroid doses low, several studies have addressed the extent to which inhaled corticosteroids might be substituted or supplemented by these drugs [14-16]. Most of these trials used lung function and symptoms as outcome variables. However, none of the trials compared changes in these measures with changes in sputum composition, exhaled NO and airway responsiveness during a stepwise reduction of steroid doses to assess the associations and dissociations between these variables and their relation to the patients' clinical state. Such data would be of interest in order to reveal whether the anti-inflammatory action of an antileucotriene manifests itself under low-dose steroids and is related to its clinical benefit.

Based on these arguments, a placebo-controlled, double-blind, randomised, parallel-group trial was performed using the oral leucotriene receptor antagonist montelukast in patients with stable bronchial asthma.

Material and methods

\section{Patients}

A total of 50 patients with the diagnosis of moderate bronchial asthma [1] were included in the 
Table 1.-Patients' characteristics at baseline

\begin{tabular}{|c|c|c|}
\hline & Montelukast & Placebo \\
\hline Subjects $n$ & 26 & 24 \\
\hline Sex M:F & $13: 13$ & $11: 13$ \\
\hline Age yrs & $38 \pm 12$ & $43 \pm 11$ \\
\hline Height $\mathrm{cm}$ & $174 \pm 7.4$ & $175 \pm 8.0$ \\
\hline FEV1 L & $3.44 \pm 0.12$ & $3.25 \pm 0.16$ \\
\hline FEV $1 \%$ pred & $95.0 \pm 2.0$ & $92.3 \pm 1.8$ \\
\hline $\mathrm{PC} 20^{\#} \mathrm{mg} \cdot \mathrm{mL}^{-1}$ & $0.771(1.34)$ & $0.856(1.20)$ \\
\hline Eosinophils in sputum $\# \%$ & $1.41(1.51)$ & $1.02(1.55)$ \\
\hline Exhaled $\mathrm{NO}$ at $50 \mathrm{~mL} \cdot \mathrm{s}^{-1 \#} \mathrm{ppb}$ & $26.8(1.20)$ & $23.6(1.12)$ \\
\hline Morning $\mathrm{PEF}^{-1} \mathrm{~L} \cdot \mathrm{min}^{-1}$ & $457 \pm 21$ & $428 \pm 26$ \\
\hline Evening $\mathrm{PEF}^{-1} \mathrm{~L} \cdot \mathrm{min}^{-1}$ & $466 \pm 21$ & $434 \pm 26$ \\
\hline Daytime symptoms score & $0.45 \pm 0.10$ & $0.86 \pm 0.19$ \\
\hline Night-time symptoms score & $0.17 \pm 0.06$ & $0.18 \pm 0.08$ \\
\hline Salbutamol ${ }^{\top}$ puffs $\cdot$ day & $1.45 \pm 0.30$ & $1.63 \pm 0.36$ \\
\hline
\end{tabular}

Values are given as arithmetic mean \pm SEM. M: male; F: female; FEV1: forced expiratory volume in one second; $\%$ pred: \% predicted; $\mathrm{PC} 20$ : provocative concentration of methacholine causing a $20 \%$ fall in FEV1; NO: nitric oxide; ppb: parts per billion; PEF: peak expiratory flow. \#: geometric mean and SEM (to be interpreted as factor); I: values assessed over 1 week during the run-in period.

trial (table 1). The forced expiratory volume in one second $(\mathrm{FEV} 1)$ was required to be $>80 \%$ predicted and the provocative concentration of methacholine causing a $20 \%$ fall in FEV1 (PC20) $<8 \mathrm{mg} \cdot \mathrm{mL}^{-1}$. All patients had inhaled corticosteroids for more than 8 weeks prior to randomisation in a dose of $800 \mu \mathrm{g}$ beclomethasone or equivalent. None of them had received oral corticosteroids or oral antihistamines within 6 months or 4 weeks, respectively, prior to entry into the study. Furthermore, it was requested that FEV1 and $\mathrm{PC}_{20}$ were reproducible within 15\% and 1.5 doubling concentrations, respectively, between visits one and two (see below). None of the patients were smokers or had signs of an acute exacerbation or respiratory tract infection within 4 weeks prior to screening.

\section{Study design}

The study comprised a total of six visits, a run-in period of 1-3 weeks duration and two treatment periods of 6 weeks each. Visit one (screening) was performed at the start of the run-in period and visit two (randomisation) was performed at the end of this period. During the run-in period patients kept the medication required for entry unchanged. In the first treatment period, they reduced the dose of inhaled corticosteroids to $50 \%$ of the run-in dose, and in the second treatment period, to $25 \%$. Depending on randomisation, patients received either montelukast $10 \mathrm{mg}$ once daily (OD) or matching placebo during both treatment periods as a daily evening dose. Only the short-acting $\beta_{2}$-agonist salbutamol was allowed for symptom relief. The last study medication was taken on the evening before laboratory visits.

At visit one, each patient's history was taken, and lung function and methacholine responsiveness were determined. Before and after the first (visits two and four) and the second (visits four and six) 6-week treatment period, lung function measurements, methacholine challenges, determinations of exhaled NO, and sputum inductions were performed in that order. Lung function was also assessed in the middle of both periods (visits three and five), without further measurements. Assessments of peak flow (PEF) and symptom scores at home were required for the duration of the study. In case of an exacerbation (defined as a decrease in PEF of $<50 \%$ compared to values at entry, or an increase in daytime symptoms of three or more or in night-time symptoms of two or more on $>3$ consecutive days) patients were asked to visit the laboratory outside the regular schedule.

The study was approved by the appropriate Ethics Committee and all patients gave their written informed consent.

\section{Measurements}

Spirometry was performed according to European Respiratory Society (ERS) guidelines [17] using a handheld spirometer. Bronchial responsiveness to methacholine was determined using a standardised validated rapid protocol [18] and changes were expressed as doubling concentrations (DC).

For measurement of exhaled NO, patients maintained predetermined expiratory flow rates $(21,33,69$, and $207 \mathrm{~m} \cdot \mathrm{Ls}^{-1}$, in duplicate) against different resistors at 20 mbar [19]. Plateau values of NO were assessed (NOA 280; Sievers Instruments Inc., Boulder, $\mathrm{CO}$, USA) and the values at precisely $50 \mathrm{~m} \cdot \mathrm{Ls}^{-1}$ were derived by interpolation. The analyser was checked after each measurement using certified calibration gas.

Sputum induction was performed as described previously [20-22]. After inhalation of $200 \mu \mathrm{g}$ salbutamol, patients inhaled 3, 4, and 5\% saline in three consecutive 10-min periods. They were asked to produce sputum during and after each period and samples were pooled for analysis. Cytospins were prepared and the percentages of nonsquamous cells were determined by two independent investigators by counting $\geqslant 400$ cells; the average of their results was taken for analysis.

For monitoring the clinical state, patients filled in diary cards for day- and night-time symptoms, with scores ranging from 0 (no symptoms) to 4 (maximal symptoms, severe impairment of daytime activities, no sleep during night-time). The use of supplemental salbutamol was documented and measurements of PEF were performed twice daily using an electronic peak-flow meter and asthma monitor (AM2; Jaeger, Höchberg, Germany) [23].

\section{Statistical analysis}

Data from all visits were included in the analysis, whereby those obtained on exacerbation (between visits five and six) were taken as visit six. Owing to the skewness of distributions, data on $\mathrm{PC} 20$, sputum eosinophils and exhaled NO (eNO) were logarithmically transformed before analysis and expressed as 
geometric mean and SEM. The geometric SEM is presented as a factor with which the geometric mean is to be multiplied or by which it is to be divided, as the multiplicative analogue of the " \pm " that pertains to the common arithmetic SEM and mean. Values of FEV1 are given as arithmetic mean values and SEM. The same applies for PEF, symptom scores and salbutamol use; these were evaluated as individual averages over consecutive 3- or 6-week periods, depending on the mode of analysis. The study was planned using PEF as primary outcome parameter. Within the parallel-group design on a $5 \%$ level of significance, the power was $\sim 80 \%$ to detect $75 \%$ protection of the deterioration under placebo by montelukast.

Data were analysed by repeated-measures analysis of variance (ANOVA) for each treatment group separately. Data obtained at 3-week intervals were used for FEV1, PEF, symptom scores and salbutamol use. For all other parameters the 6-week data was used. Comparisons between visits within groups were performed using the Newman-Keuls test. ANOVA was also used to compare groups with each other, again using visits as within-factor. Respiratory symptoms were analysed by Friedman's ANOVA in each treatment group separately, but groups were compared with each other using standard ANOVA. Correlations were evaluated using Pearson's linear correlation coefficient. Statistical significance was assumed for $\mathrm{p}<0.05$.

\section{Results}

Initially, 56 patients were included in the study, but six patients had to be excluded due to different causes within the first 3 weeks (e.g. lack of compliance or cooperation, personal reasons etc.). Data from these patients were excluded from further analysis.

Five patients of the patients included had to be discontinued due to an exacerbation of their bronchial asthma; three of them had received montelukast, and two placebo. All exacerbations occurred between visits five and six, i.e. during the last 3 weeks after reduction of the steroid dose to $25 \%$. These patients were included in the final analysis, and the data on exacerbation were taken as end-point equivalents to visit six.

With regard to the values assessed at screening (visit one) or baseline (visit two), none of the parameters showed statistically significant differences between groups or visits one and two.

\section{Lung function}

During treatment with placebo, significant changes in FEV1 occurred over the two reduction periods $(\mathrm{p}<0.001$, ANOVA; table 2, fig. 1a). Specifically, the values measured during and at the end of the second reduction period were different from those measured before ( $p<0.01$, Newman-Keuls test), which were not significantly different from each other. At the end of the study, the mean \pm SEM decrease in FEV1 compared to baseline was $252 \pm 65 \mathrm{~mL}$.

During treatment with montelukast, FEV1 declined in a similar way $(\mathrm{p}<0.001)$. Again the values assessed during and at the end of the second reduction period were different from those measured before $(p<0.01)$, while these were not different from each other. On the last visit, the fall in FEV1 compared to baseline was $205 \pm 72 \mathrm{~mL}$.

There were no statistically significant differences between groups regarding the time course of FEV1, neither in absolute terms nor in per cent predicted.

\section{Airway responsiveness to methacholine}

Changes in PC20 were not statistically significant in the placebo group (table 2, fig. 1b). At the end of the study, mean \pm SEM PC20 had decreased by $0.44 \pm 0.32$ DC compared to baseline.

In the montelukast group, the changes in PC20 were

Table 2. - Changes in different parameters observed over the two treatment periods

\begin{tabular}{|c|c|c|c|c|}
\hline & \multicolumn{2}{|c|}{ 1st reduction period } & \multicolumn{2}{|c|}{2 nd reduction period } \\
\hline & Placebo & Montelukast & Placebo & Montelukast \\
\hline FEV1 $\mathrm{mL}$ & $-58 \pm 49$ & $23 \pm 41$ & $-194 \pm 57^{+}$ & $-227 \pm 72^{+}$ \\
\hline $\mathrm{PC}_{20} \mathrm{DC}$ & $0.15 \pm 0.28$ & $0.35 \pm 0.25$ & $-0.60 \pm 0.29$ & $-0.26 \pm 0.18$ \\
\hline Exhaled $\mathrm{NO}^{\#} \mathrm{ppb}$ & $1.23(1.12)$ & $1.02(1.13)$ & $1.06(1.18)$ & $1.09(1.13)$ \\
\hline Eosinophils in sputum $\#$ & $1.52(1.37)$ & $1.11(1.33)$ & $1.65(1.44)^{*}$ & $1.48(1.36)$ \\
\hline Morning PEF $\mathrm{L} \cdot \mathrm{min}^{-1}$ & $-10.2 \pm 5.0$ & $-2.8 \pm 5.7$ & $-19.9 \pm 5.9^{+}$ & $-20.2 \pm 5.6^{+}$ \\
\hline Evening $\mathrm{PEF}^{-1} \mathrm{~L} \cdot \mathrm{min}^{-1}$ & $-9.3 \pm 5.6$ & $-0.3 \pm 5.6$ & $-11.9 \pm 4.7^{+}$ & $-18.5 \pm 5.0^{+}$ \\
\hline Daytime symptoms score & $-0.03 \pm 0.09$ & $0.11 \pm 0.07$ & $0.21 \pm 0.10$ & $-0.29 \pm 0.11^{*, * * *}$ \\
\hline Night-time symptoms score & $0.02 \pm 0.04$ & $-0.02 \pm 0.05$ & $0.13 \pm 0.05^{*}$ & $0.09 \pm 0.06$ \\
\hline Salbutamol puffs $\cdot$ day $^{-1}$ & $0.25 \pm 0.29$ & $0.19 \pm 0.12$ & $0.46 \pm 0.25^{*}$ & $0.30 \pm 0.34$ \\
\hline
\end{tabular}

Arithmetic mean \pm SEM of changes over the two consecutive 6 -week periods are given (1st period: visit 2 versus 4; 2nd period: visit 4 versus 6 ). FEV1: forced expiratory volume in one second; PC20: provocative concentration of methacholine causing a $20 \%$ fall in FEV1; DC: doubling concentrations; NO: nitric oxide; ppb: parts per billion; PEF: peak expiratory flow. \#: Geometric mean values (SEM) of changes (both to be interpreted as factor); ${ }^{\natural}$ : based on values averaged over the respective 6-week periods; data are given as changes relative to baseline (1st period) and relative to each other (2nd period); ${ }^{*}: \mathrm{p}<0.05$; ${ }^{+}: \mathrm{p} \leqslant 0.001$ (total change over time by analysis of variance (ANOVA)); ${ }^{* *}: \mathrm{p}<0.001$, difference between groups (ANOVA, interaction term). 

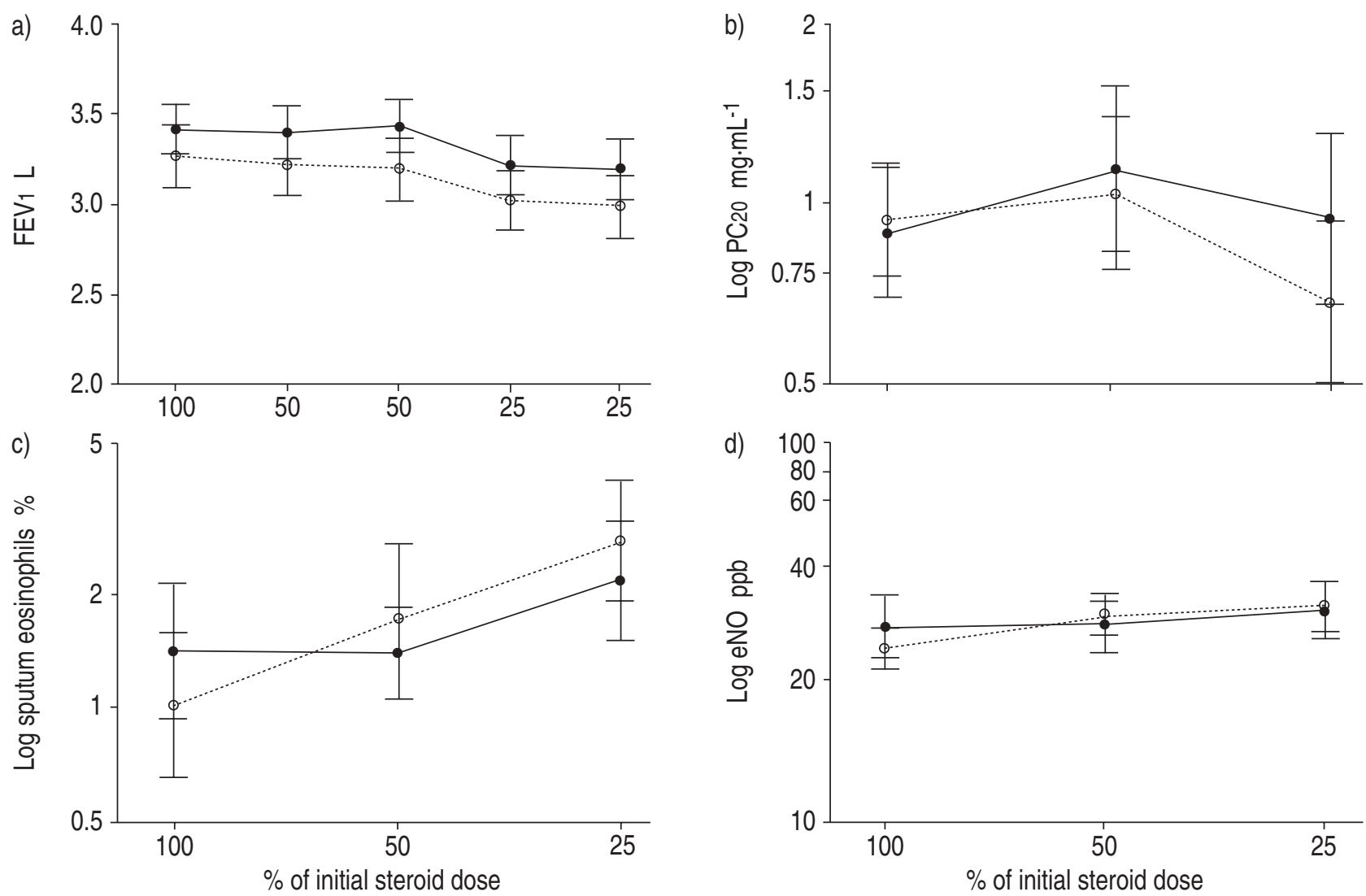

Fig. 1.-Course of a) forced expiratory volume in one second (FEV1), b) provocative concentration of methacholine causing a $20 \%$ fall in FEV1 (PC20), c) sputum eosinophils, and d) the level of exhaled nitric oxide (eNO) during the study. Values were measured at the start (baseline, 100\%), as well as in the middle (some parameters) and at the end (all parameters) of the two consecutive 6-week steroid reduction periods. The first period is indicated by $50 \%$ and the second by $25 \%$. $\bigcirc$ : placebo; 0 : montelukast. The values of PC20, sputum eosinophils and eNO were measured only at the start (baseline) and at the end of the two steroid reduction periods. Note that they are given on a $\log$ scale owing to their distribution. For levels of significance see text. ppb: parts per billion.

also not statistically significant from zero. At the end of the study, PC20 was increased by $0.09 \pm 0.29$ DC compared to baseline. There were no statistically significant differences between groups in the course of PC20.

\section{Induced sputum}

In the placebo group, the percentage of eosinophils in induced sputum increased significantly $(\mathrm{p}=0.018)$ over both reduction periods (table 2, fig. 1c). Specifically, values measured at baseline and after the second period were different from each other $(p<0.05)$. On average (SEM), eosinophils rose by a factor of 2.66 (1.34) compared to baseline.

Percentages of eosinophils also increased in the montelukast group, with the total rise at the end of the study being by factor 1.49 (1.45). These changes were not statistically significant. In addition, the course of sputum eosinophils did not differ significantly between groups. Also, the percentages of neutrophils did not change significantly over time or with treatment regimens.

\section{Exhaled nitric oxide}

With placebo, the level of eNO increased over both reduction periods (table 2, fig. 1d) but the changes were not statistically significant. At the end of the study, NO rose on average (SEM) by a factor of 1.31 (1.13) compared to baseline.

NO levels also slightly increased in the montelukast group, with the total increase at the end of the study being by a factor of 1.12 (1.19). These changes were also not statistically significant. Furthermore, values of eNO did not differ significantly between groups.

\section{Peak expiratory flow}

Within the placebo group, both morning and evening PEF decreased significantly over time $(p<0.001$, each; fig. $2 a$ and b). Changes were significant during the second reduction period compared to the previous values (table 2). In the second period, the mean \pm SEM fall of PEF against baseline was 30.1 \pm 7.3 and $21.2 \pm 8.1 \mathrm{~L} \cdot \mathrm{min}^{-1}$, respectively.

There were also significant $(p \leqslant 0.001$, each) effects with montelukast, the overall fall in PEF in the second 

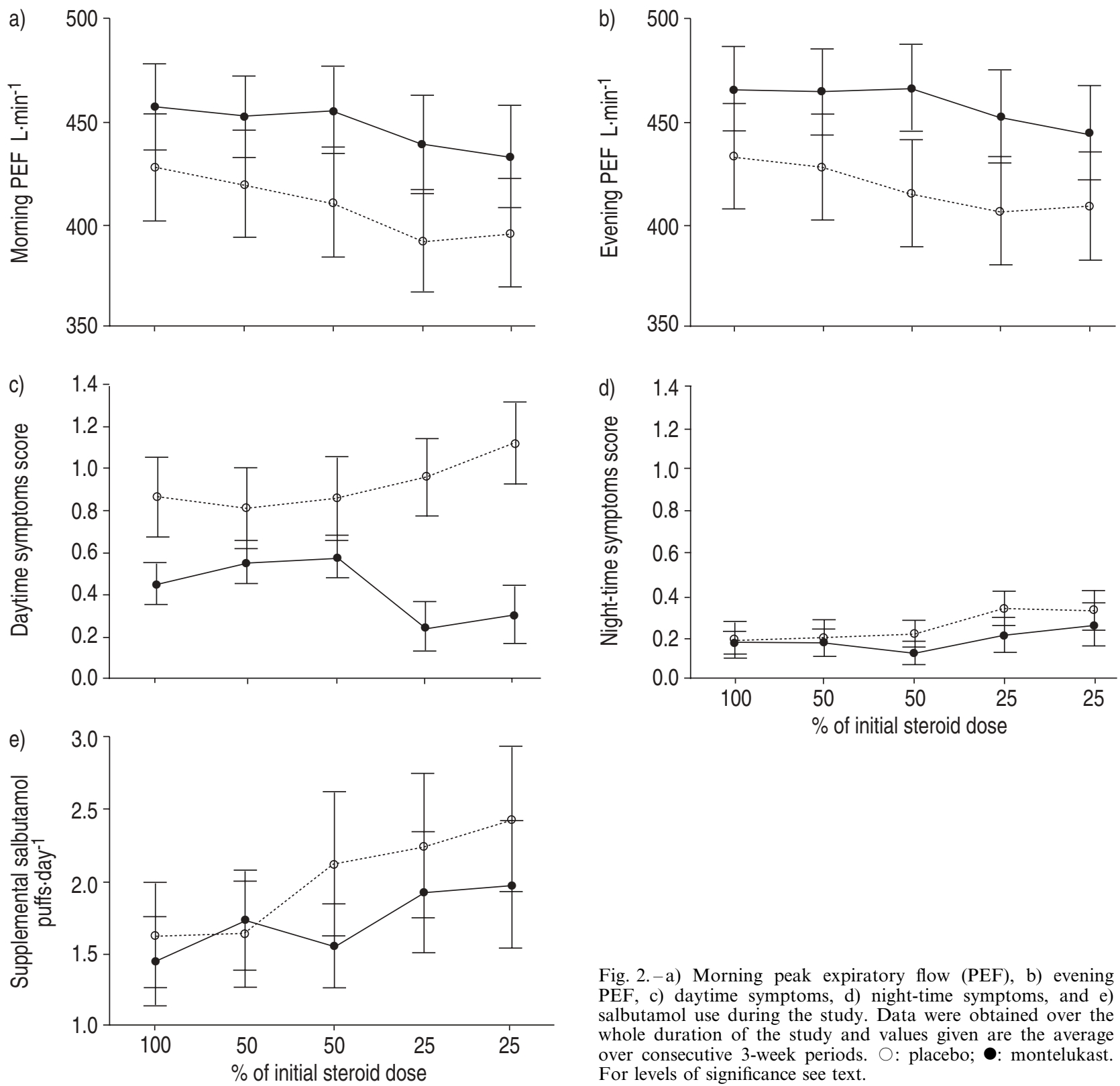

Fig. 2.-a) Morning peak expiratory flow (PEF), b) evening PEF, c) daytime symptoms, d) night-time symptoms, and e) salbutamol use during the study. Data were obtained over the whole duration of the study and values given are the average over consecutive 3-week periods. $\bigcirc$ : placebo; $\bullet$ : montelukast. For levels of significance see text.

reduction period being $23.2 \pm 8.0$ and $19.4 \pm 9.2 \mathrm{~L} \cdot \mathrm{min}^{-1}$. Again, statistical significance was achieved in the second period versus the previous data. There was no significant difference between groups regarding the course of either morning or evening PEF.

\section{Respiratory symptoms and use of salbutamol}

In the placebo group, changes in daytime symptoms were not statistically significant but those in nighttime symptoms were ( $\mathrm{p}=0.047$; fig. $2 \mathrm{c}$ and $\mathrm{d}$ ). There was also a significant rise in the use of salbutamol ( $p=0.036$; fig. 2e). Overall, the mean \pm SEM changes against baseline in the second reduction period were $0.18 \pm 0.15$ and $0.15 \pm 0.06$ score units, respectively, and $0.71 \pm 0.44$ puffs $\cdot$ day $^{-1}$.
With montelukast there was a significant change in daytime ( $\mathrm{p}=0.024)$ but not in night-time symptoms, and no change in the use of salbutamol. In the last period of the trial the changes against baseline were $-0.18 \pm 0.11$ and $0.07 \pm 0.07$ score units, and $0.50 \pm$ 0.39 puffs $\cdot$ day $^{-1}$. The course over the two reduction periods differed significantly between groups in the case of daytime symptoms $(\mathrm{p}<0.001$, ANOVA interaction term).

\section{Discussion}

The present study compared the effects of a dose reduction of inhaled corticosteroids on lung function and indirect markers of airway inflammation in 
the presence or absence of the leucotriene receptor antagonist montelukast. In the patients studied, no significant effects occurred following a reduction to $50 \%$ of the dose at entry. After further reduction to $25 \%$ there was a slight but consistent fall in lung function, both in the presence and absence of montelukast. At the same time, methacholine responsiveness, the percentage of eosinophils in sputum and the level of exhaled NO, as an additional marker of eosinophil-associated inflammation, rose, but most of these effects were not statistically significant; however, changes tended to be smaller with montelukast. Daytime symptoms showed small but statistically significant beneficial effects of montelukast relative to placebo. These findings can be reconciled when assuming that, under low-dose corticosteroids, montelukast achieved its clinical benefits not through modulation of a single parameter but through a combined effect of small changes in different parameters.

All patients included fulfilled the criteria of moderate asthma as defined by recent guidelines [1], and the initial dose of inhaled corticosteroids, which had led to a stable clinical condition before entry into the study, was considered appropriate by the treating physicians. Overtreatment, however, is an issue of considerable importance [15], particularly as the classification of the severity of a patient's disease in the presence of treatment poses a major problem. The study protocol therefore comprised two steps of reduction, the first one to $50 \%$ and the second $25 \%$ of the initial steroid dose. No significant changes were observed over the first reduction period, but interestingly, there was a tendency towards an early onset of the decrease in FEV1 and PEF in the placebo group (table 2). This suggests that, despite being considered adequate, the dose of steroids could have been lowered without relevant changes in the quantities measured. Overall, these observations confirm the suspicion of overtreatment in the majority of patients. This controversial issue, however, cannot be considered to be being resolved, since other data have indicated that treatment with steroid doses higher than those derived from guidelines might lead to a reduction of morphological alterations in asthma, as detectable by invasive procedures [2].

Only the second reduction led to significant effects on lung function and symptoms. Changes in FEV1 as well as PEF were of similar magnitude when compared between the two groups. Expressed as per cent fall against baseline, changes of both parameters were also similar to each other. As patients had taken their study medication regularly the evening before laboratory visits, it therefore appeared that the bronchodilator effect of montelukast did not last until the next morning. Overall, symptom scores were low in the patients studied, and this has to be considered in the interpretation of the results. Nonetheless, frequencies of symptoms and salbutamol inhalations were lower in the montelukast compared to the placebo group (table 2), in accordance with other studies [15]. Interestingly, the effect of montelukast was most clearly seen in daytime symptoms. The present authors do not have an explanation for the dissociation between symptoms and functional changes but it could indicate that either symptomatic improvements were most relevant at times when lung function data were not available (e.g. during daytime, see table 2), or that, for example, the small and statistically nonsignificant differences in the indirect measures of airway inflammation played a role, as a combined effect.

The number of exacerbations, which did not differ between the two groups, was too low to judge a potential effect of montelukast. However, when analysing whether patients experiencing an exacerbation in any of the groups conveyed particular baseline characteristics, four of the five patients were found to show a PC20 on entry that was below average (table 1). These data are in accordance with previous findings that patients exhibiting marked hyperresponsiveness in the presence of steroids were those at highest risk when steroids were withdrawn [24]. The present study also assessed whether the data measured on the last visit before exacerbation showed any sign of an ongoing or impending deterioration. Within the limits set by the small number of patients, no such pattern was recognisable.

All patients were hyperresponsive to inhaled methacholine at baseline, despite steroid treatment (table 1). In contrast, mean FEV1 was near normal values. Similarly, the percentage of eosinophils in sputum and the concentration of exhaled NO were close to values from healthy subjects and lower than in patients with asthma not under corticosteroids [19]. These findings obviously reflect the differential effect of steroids on different parameters. Nonspecific airway responsiveness is probably one of those indices that are only marginally affected by short-term treatment with steroids and never shifted into the normal range. Whether methacholine responsiveness possesses a predictive value has been a matter of debate [25], and this may apply mainly to longterm effects of steroid treatment [2]. With regard to sputum eosinophils or exhaled $\mathrm{NO}$, there are no data currently at hand from large prospective studies that have used these parameters for therapeutic management and demonstrated their clinical value in addition to conventional clinical or functional measures [26].

The scatter of the data obtained for the indirect measures of airway inflammation might increase suspicion that measurements were subject to unacceptably large errors. There was, however, no sign of a more than usual variability of PC20, sputum or NO determinations. The present authors have previously demonstrated that using an equivalent method, PC20 can be determined within less than \pm 0.5 doubling concentrations [27]. Secondly, the NO analyser was calibrated after each measurement to correct for drifts over the day, and plateau values at precisely $50 \mathrm{~mL} \cdot \mathrm{s}^{-1}$ were derived by interpolation from $\mathrm{NO} /$ flow curves. Values were thus independent of variations in the targeted flow rate [19]. Thirdly, based on previous experience in sputum analysis [21], this procedure had been used to reveal anti-inflammatory effects of corticosteroids [22]. The authors therefore believe that the scatter as observed reflected the natural 
variability over the 3-12 week intervals of the study. Comparitively, variability of FEV1 determinations was much lower, possibly because, in the patients of the severity studied, its variability was more restricted by, for example, physical characteristics and the indices of inflammation were more strongly affected by random influences from the environment. This finding underscores the assertion that the clinical addon value of noninvasive parameters versus lung function still needs to be established [24] and that this value may well differ in different groups of patients or conditions.

Significant clinical benefits as well as functional effects of montelukast have been established in a number of large multicentre trials [15, 28]. Not all studies, however, reported on such effects, including an anti-inflammatory action of montelukast [12]. In contrast to the expected $75 \%$ protection of the deterioration in PEF under placebo, the actual protection through montelukast was $\sim 20 \%$ and was nonsignificant. With regard to the time course within groups, the power was much higher as reflected in the low respective $p$-values for PEF and FEV1. In addition, no statistical evidence for a significant action of montelukast on indices of airway inflammation or airway responsiveness was found either within or between groups. Despite the limited power regarding each of the single variables and the tendency toward a weaker response with montelukast in all of them, the overall pattern did not support a major anti-inflammatory potency of montelukast, in the presence of low-dose corticosteroids. This seems to be a most important caveat, since changes within the placebo group were also nonsignificant except for sputum eosinophils, demonstrating that $25 \%$ of the initial steroid dose was still sufficient to prevent a significant rise in airway responsiveness or exhaled NO. The presence of lowdose steroids may also explain part of the discrepancy between the data of this study and papers reporting anti-inflammatory effects of antileucotrienes, such as a reduction in eosinophils [10] and exhaled NO [11] or an attenuation of allergen responses $[13,29]$. Irrespective of the questionable effects of montelukast on functional and anti-inflammatory indices in the present study, the differences in symptom frequency indicated a clinical benefit even in the presence of inhaled corticosteroids.

In conclusion, the present study demonstrates that a reduction in inhaled corticosteroids to $25 \%$ of the initial dose in patients with asthma led to a slight fall in lung function that was not attenuated by montelukast and, at the same time, to changes in symptoms that were partially prevented by montelukast. Indirect measures of airway inflammation showed a larger variability than lung function and did not provide statistical evidence for significant effects of montelukast. Thus, under the conditions of the present study, their add-on value for determining the patients' clinical state seemed questionable. Furthermore, the data suggest that, in the presence of low-dose steroids, clinical benefits of montelukast might not be traced to single measures of airway function but are reflected in combined, although weak, effects on a number of parameters.

\section{References}

1. National Institutes of Health. National Heart, Lung and Blood Institute. Expert panel report 2: Guidelines for the diagnosis and management of asthma. Publication 97-4051. Bethesda, MD, National Heart, Lung and Blood Institute, 1997.

2. Sont JK, Van Krieken JHJM, Evertse CE, Hooijer R, Willems LN, Sterk PJ. Relationship between the inflammatory infiltrate in bronchial biopsy specimens and clinical severity of asthma in patients treated with inhaled steroids. Thorax 1996; 51: 496-502.

3. Pizzichini MMM, Pizzichini E, Clelland L, et al. Prednisone-dependent asthma: in inflammatory indices in induced sputum. Eur Respir $J$ 1999; 13: 15-21.

4. van Rensen ELJ, Straathof KCM, Veselic-Charvat MA, Zwinderman AH, Bel EH, Sterk PJ. Effect of inhaled steroids on airway hyperresponsiveness, sputum eosinophils and exhaled nitric oxide levels in patients with asthma. Thorax 1999; 54: 403-408.

5. in't Veen JC, De Gouw HW, Smits HH, et al. Repeatability of cellular and soluble markers of inflammation in induced sputum from patients with asthma. Eur Respir J 1996; 9: 2441-2447.

6. Barnes PJ, Kharitonov SA. Exhaled nitric oxide: a new lung function test. Thorax 1996; 51: 233-237.

7. Lötvall J, Inman M, O'Byrne P. Measurement of airway hyperresponsiveness: new considerations. Thorax 1998; 53: 419-424.

8. Wenzel S, Szefler SJ, Leung DY, Sloan SI, Rex MD, Martin RJ. Bronchoscopic evaluation of severe asthma: persistent inflammation associated with high dose glucocorticoids. Am J Respir Crit Care Med 1997; 156: 737-743.

9. Azevedo I, de Blic J, Scheinmann P, Vargaftig BB, Bachelet M. Enhanced arachidonic acid metabolism in alveolar macrophages from wheezy infants: modulation by dexamethasone. Am J Respir Crit Care Med 1995; 152: 1208-1214.

10. Pizzichini E, Leff JA, Reiss TF, et al. Montelukast reduces airway eosinophilic inflammation in asthma: a randomized, controlled trial. Eur Respir J 1999; 14: 12-18.

11. Bisgaard H, Loland L, Anhøj J. NO in exhaled air of asthmatic children is reduced by the leukotriene receptor antagonist montelukast. Am J Respir Crit Care Med 1999; 160: 1227-1231.

12. Kanniess F, Richter K, Böhme S, Jörres RA, Magnussen H. Montelukast versus fluticasone: effects on lung function, airway responsiveness and inflammation in moderate asthma. Eur Respir $J$ 2002; 20: 853-858.

13. Richter K, Grönke L, Janicki S, Hermann R, Virnkaes C, Magnussen H. Protective effect of azelastine, montelukast, and their combination on early and late phase of allergen induced bronchoconstriction in patients with asthma. Am J Respir Crit Care Med 2001; 163: A430.

14. Drazen JM, Israel E, O'Byrne PM. Treatment of asthma with drugs modifying the leukotriene pathway. $N$ Engl J Med 1999; 340: 197-206.

15. Löfdahl CG, Reiss TF, Leff LA, et al. Randomised, placebo controlled trial of effect of a leukotriene receptor antagonist, montelukast, on tapering inhaled corticosteroids in asthmatic patients. BMJ 1999; 319: 87-90.

16. Tamaoki J, Kondo M, Sakai N, et al. Leukotriene 
antagonist prevents exacerbation of asthma during reduction of high-dose inhaled corticosteroid. Am J Respir Crit Care Med 1997; 155: 1235-1240.

17. Quanjer PH, Tammeling GJ, Cotes JE, Pedersen OF, Peslin R, Yernault JC. Lung volumes and forced ventilatory flows. Report working party standardization of lung function tests, European Community for Steel and Coal. Official statement of the European Respiratory Society. Eur Respir J 1993; 6: Suppl. 16, s5-s40.

18. Jörres RA, Nowak D, Kirsten D, Grönke L, Magnussen H. A short protocol for methacholine provocation testing adapted to the Rosenthal-Chai dosimeter technique. Chest 1997; 111: 866-869.

19. American Thoracic Society. Recommendations for standardized procedures for the online and offline measurement of exhaled lower respiratory nitric oxide and nasal nitric oxide in adults and children. $\mathrm{Am}$ J Respir Crit Care Med 1999; 160: 2104-2117.

20. Holz O, Jörres RA, Koschyk S, Speckin P, Welker L, Magnussen $\mathrm{H}$. Changes in sputum composition during sputum induction in healthy and asthmatic subjects. Clin Exp Allergy 1998; 28: 284-292.

21. Kanniess F, Richter K, Böhme S, Jörres RA, Magnussen $H$. Effect of inhaled Ciclesonide on airway responsiveness to inhaled AMP, the composition of induced sputum and exhaled nitric oxide in patients with mild asthma. Pulm Pharmaco Ther 2001; 14: 141-147.

22. Richter K, Holz O, Jörres RA, Mücke M, Magnussen $\mathrm{H}$. Sequentially induced sputum in patients with asthma or chronic obstructive pulmonary disease. Eur Respir J 1999; 14: 697-701.

23. Richter K, Kanniess F, Mark B, Jörres RA, Magnussen H. Assessment of accuracy and applicability of a new electronic peak flow meter and asthma monitor. Eur Respir J 1998; 12: 457-462.

24. Magnussen H, Willenbrock U, Jörres RA. Duration of the effect of inhaled corticosteroids on lung function and sensitivity of the respiratory tract in patients with bronchial asthma. Med Klin 1995; 90: 214-219.

25. Brusasco V, Crimi E, Pellegrino R. Airway hyperresponsiveness in asthma: not just a matter of airway inflammation. Thorax 1998; 53: 992-998.

26. Magnussen $\mathrm{H}$, Holz $\mathrm{O}$, Sterk PJ, Hargreave FE. Noninvasive methods to measure airway inflammation: future considerations. Eur Respir J 2000; 16: 1175-1179.

27. Bonnet R, Jörres R, Heitmann U, Magnussen H. Circadian rhythm in airway responsiveness and airway tone in patients with mild asthma. J Appl Physiol 1991; 71: 1598-1605.

28. Salvi SS, Krishna MT, Sampson AP, Holgate ST. The anti-inflammatory effects of leukotriene-modifying drugs and their use in asthma. Chest 2001; 119: $1533-1546$.

29. Diamant Z, Grootendorst DC, Veselic-Charvat M, et al. The effect of montelukast (MK-0476), a cysteinyl leukotriene receptor antagonist, on allergen-induced airway responses and sputum cell counts in asthma. Clin Exp Allergy 1999; 29: 42-51. 